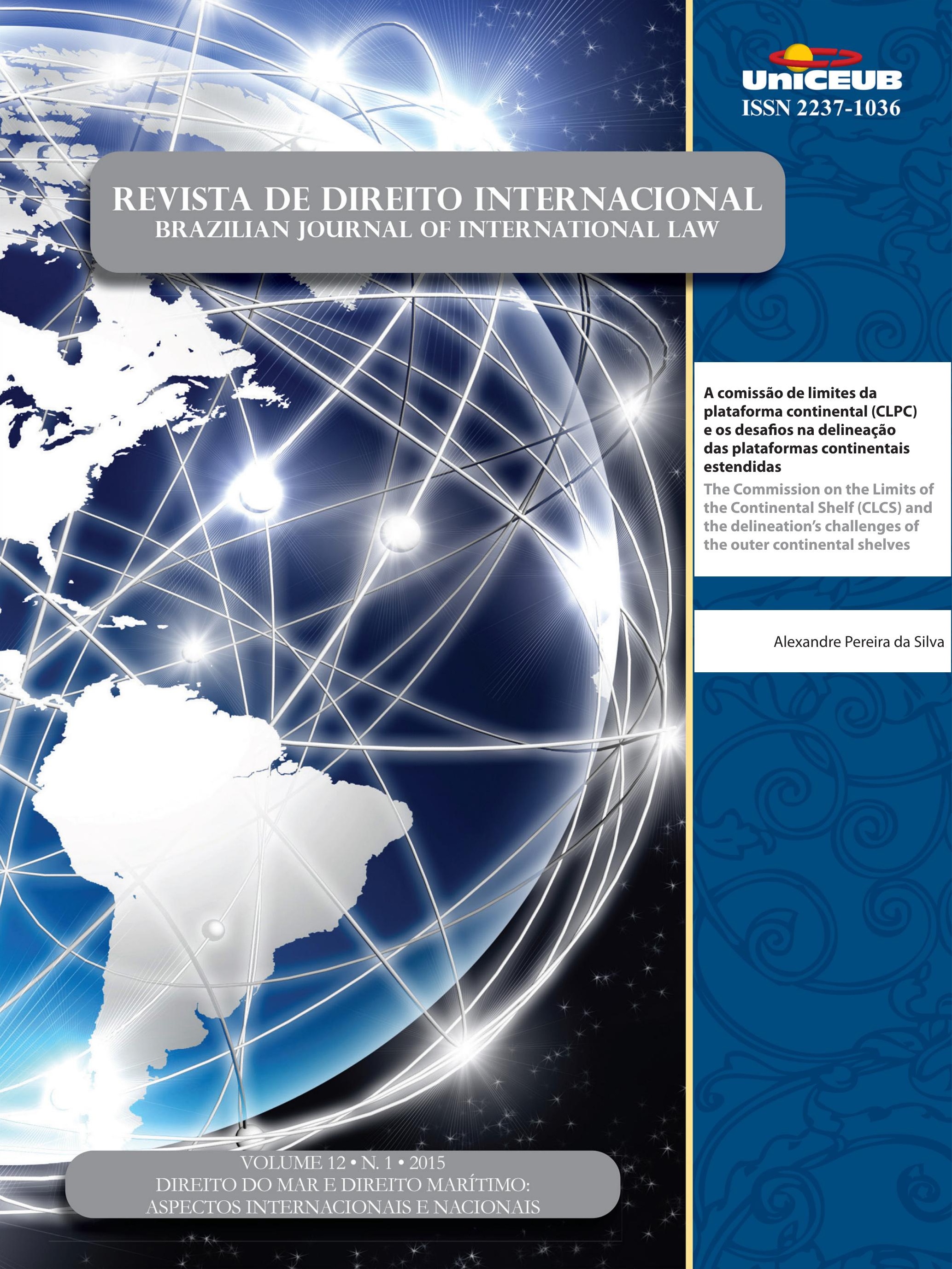




\section{Sumário}

\section{Crônicas}

CRôNICAS DA ATUALIDADE do DiREITO INTERNACIONAL ........................................................ 2

Nitish Monebhurrun (org.)

Towards a european regulation of the importation of conflict minerals?..... 2

Nitish Monebhurrun

Keeping up with the terrorists: the EU's proposed Passenger Name Records (PNR) Directive \& european security

Eshan Dauhoo

A histórica reaproximação de Cuba e EUA

Erika Braga

A contextualização da atual reivindicação da Grécia para receber indenizações por atos da Alemanha durante a Segunda Guerra Mundial . .10

Natália da Silva Gonçalves

José Eduardo Paiva Miranda de Siqueira

Crônicas da jurisprudência do Direito Internacional (CIJ/ITLOS): Decisões da Corte Internacional de Justiça e do Tribunal Internacional Sobre o Direito do Mar .14

Nitish Monebhurrun (Org.)

Corte Internacional de Justiça

Estudo da decisão da Corte Internacional de Justiça no caso Croácia v. Servia (03/02/2015) .14

Liziane Paixão Silva Oliveira e Maria Edelvacy Marinho

Questões relacionadas com a apreensão e detenção de certos documentos e dados: (Timor Leste c. Austrália) - O reconhecimento do retorno de uma relação amigável entre Timor-Leste e Austrália e a nova decisão da CIJ, 6 de maio de 2015 . 20

Gleisse Ribeiro Alves

Tribunal Internacional sobre Direito do Mar

Caso da delimitação da fronteira marítima entre o Gana e a Costa do Marfim no Oceano Atlântico: medidas cautelares $(25 / 04 / 2015)$

Nitish Monebhurrun

Comentário à Opinião Consultiva 21 do Tribunal Internacional para o Direito Do Mar [02/04/2015] (Responsabilidade do Estado de Bandeira pela pesca ilícita, não declarada ou não regulamentada) ...............25

Carina Costa de Oliveira 
CRÔNICAS DO DIREITO INTERNACIONAL DOS INVESTIMENTOS

Nitish Monebhurrun (Org.)

A inclusão da responsabilidade social das empresas nos novos Acordos de Cooperação e de Facilitação dos Investimentos do Brasil: uma revolução 33

Nitish Monebhurrun

\section{O Direito do Mar Perante as JuRisdições INTERnacionais}

CoAstal States' Rights IN THE MARITIME AREAS UNDER UNCLOS .40 Tullio Treves

TACKling illegal, unregulated And unReported Fishing: THE ITLOS Advisory OpINION on Flag State Responsibility for IUU fishing AND THE PRINCiple of DUE DiligenCE ...50 Victor Alencar Mayer Feitosa Ventura

REFLEXões PROVENIENTES do DisSENSO: UMA ANÁLISE CRÍtica A RESPEITO do CASO Austrália versus Japão Perante a Corte InTERnacional de JustiçA .......................................68 Luciana Ferna ndes Coelho

Os TRATADOS INTERNACIONAIS DE DIREITO DO MAR E SEUS EFEITOS SOBRE TERCEIROS ESTADOS ..... 86 Tiago V. Zanella

\section{InStRumentos JURÍdicos PARA A GeStÃo do MAR}

OS LIMITES DOS TERMOS BEM PÚBLICO MUNDIAL, PATRIMÔNIO COMUM DA HUMANIDADE E BENS COMUNS PARA DELIMITAR AS OBRIGAÇÕES DE PRESERVAÇÃO DOS RECURSOS MARINHOS 109 Carina Costa de Oliveira e Sandrine Maljean-Dubois

Os limites do PLANEJAMENTO DA OCUPAÇÃo SUSTENTÁVEL DA ZONA COSTEIRA BRASILEIRA ... 126 Carina Costa de Oliveira e Luciana Coelho

CORRENDO PARA O MAR NO ANTROPOCENO: A COMPLEXIDADE DA GOVERNANÇA DOS OCEANOS E A ESTRATÉGIA BRASILEIRA DE GESTÃO DOS RECURSOS MARINHOS 
A comissão de limites da Plataforma continental (CLPC) E Os DESAFios Na delineaÇÃo DAS PLATAFORMAS CONTINENTAIS ESTENDIDAS................................................... 170

Alexandre Pereira da Silva

\section{A PROTEÇÃo DO MEIO AMBIENTE MARINHO}

O gRANDE JOGo do ÁrTiCo: REFLEXões COM BASE NA PERSPECTIVA DE EXPLORAÇão ECONÔMICA

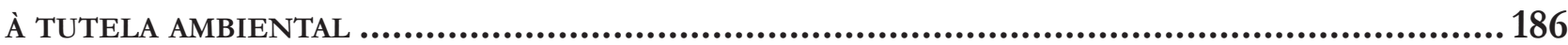

Fernando Rei e Valeria Cristina Farias

Instrumentos Públicos e Privados para a reparação do dano ambiental causado por DERRAMAMENTO DE ÓLEO NO MAR SEM ORIGEM DEFINIDA: AS MANCHAS ÓRFÃS

Renata Brockelt Giacomitti e Katya R. Isaguirre-Torres

O DIREITO INTERNACIONAL PRIVADO E A RESPONSABILIDADE CIVIL EXTRACONTRATUAL POR DANOS AMBIENTAIS CAUSADOS POR TRANSPORTES MARÍTIMOS À LUZ DO DIREITO BRASILEIRO ....... 217 Inez Lopes

A NECESSIDADE DE REPENSAR OS MECANISMOS DE RESPONSABILIDADE AMBIENTAL EM CASO DE riscos de VAZamento de PETRóleo Na Zona Econômica Exclusiva do BrasiL

Marcelo D. Varella

\section{Problemáticas do Direito Marítimo}

A FisCALIZAÇão SANitÁRIA DAS EMBARCAÇÕES EM ÁGUAS JURISDICIONAIS BRASILEIRAS: NOTAS aCERCA da (IN)efetividade da Súmula 50 da AGU

Joedson de Souza Delgado e Ana Paula Henriques da Silva

A IMO E A REPRESSÃo AO ROUBO ARMADO CONTRA NAVIOS: DA RETÓRICA INTERNACIONAL À COOPERAÇÃO REGIONAL

André Panno Beirão e Charles Pacheco Piñon

\section{O Direito do Mar diante da Pirataria}

O DIREITO INTERNACIONAL EM FACE DA PIRATARIA EM ALTO-MAR: UMA PERSPECTIVA CRÍTICA.289 Maiquel Ângelo Dezordi Wermuth e Rafaela Correa 
Pirataria marítima: A EXPERIÊnCIA Somália

Eduardo Augusto S. da C. Schneider

\section{Temas Gerais}

DRAWING THE LINE: ADDRESSING ALLEGATIONS OF UNCLEAN HANDS IN INVESTMENT ARBITRATION*

Mariano de Alba

Para Que Serve a história do Direito internacional?

George Rodrigo Bandeira Galindo

As interferências entre a Política Externa e de Segurança Comum Europeia (Pesc) e O DiREITO DAS NaÇões UNIDAS

Leonardo de Camargo Subtil

Introdução Às regras de aplicaÇão da Convenção da ONU Sobre Contratos de ComPRA E VENDA INTERNACIONAL DE MERCADORIAS E O DIREITO INTERNACIONAL PRIVADO BRASI-

LEIRO 380

Paul Hugo Weberbauer e Eugênia Cristina Nilsen Ribeiro Barza

A REgulaÇÃo das EMPRESAS TRANSNACIONAIS ENTRE AS ORDENS JURÍDICAS ESTATAIS E NÃO ESTATAIS.

Mateus de Oliveira Fornasier e Luciano Vaz Ferreira

OUtLAWING HATE SPEECH IN DEMOCRATIC STATES: THE CASE AGAINST THE INHERENT LimitAtions doctrine concerning Article 10 (1) of the European Convention on Human

Rights 416

Stefan Kirchner 


\title{
A comissão de limites da plataforma continental (CLPC) e os desafios na delineação das plataformas continentais estendidas*
}

\author{
The Commission on the Limits of \\ the Continental Shelf (CLCS) and the \\ delineation's challenges of the outer \\ continental shelves
}

Alexandre Pereira da Silva**

\section{Resumo}

O objetivo deste artigo consiste em analisar o papel que a Comissão de Limites da Plataforma Continental (CLPC) vem desempenhando no processo de delineação das plataformas continentais estendidas. Este estudo estruturou-se em uma perspectiva teórico-prática, por meio da qual a atuação da CLPC foi utilizada como paradigma para descrever os debates acadêmicos em torno da possibilidade de os Estados costeiros ampliarem suas plataformas continentais além do limite das 200 milhas marítimas. Dessa forma, o trabalho apresenta alguns resultados para a hipótese de que a CLPC vem enfrentando sérios desafios no desempenho de suas funções: considerável volume de trabalho, restrições financeiras e a participação de terceiros Estados interessados nas submissões de Estados costeiros. Por fim, a contribuição original do presente trabalho consiste em traçar um painel da CLPC desde sua formação até o momento atual, agregando debates teóricos com casos práticos apresentados à CLPC.

Palavras-chave: Direito do Mar. Plataforma Continental. Comissão de Limites da Plataforma Continental. Desafios.

\section{Abstract}

The goal of this paper is to analyze the role of the Commission on the Limits of the Continental Shelf (CLCS) in the developing of the outer continental shelves delineation process. The research was structured in a theoretical and practical approach; the performance of the CLCS was used as a paradigm to describe the academic debates around the possibility of coastal States to extend their continental shelves beyond 200 nautical miles. In that way, the study presents some results for the hypothesis that the CLCS is facing serious challenges in the performance of its duties: considerable workload, financial restrictions and the third party intervention in the coastal States' submissions. Finally, the original contribution of the present work consists of drawing a picture of the CLCS since its formation to the

** Pós-Doutor em Direito pela Schulich School of Law, Dalhousie University, Halifax, Canadá. Professor Adjunto de Direito Internacional da Faculdade de Direito do Recife/ Universidade Federal de Pernambuco (FDR/ UFPE). E-mail: lpsilva.alexandre@gmail.com

Recebido em 27/04/2015 Aprovado em 06/06/2015 
present date, adding theoretical debates with practical cases presented to the CLCS.

Keywords: Law of the Sea. Continental Shelf; Commission on the Limits of the Continental Shelf. Challenges.

\section{INTRODUÇÃO}

O papel da Comissão de Limites da Plataforma Continental (doravante Comissão ou CLPC) é bastante peculiar, visto que a maioria dos Estados não utilizará dos seus serviços. Todavia, as decisões e recomendações tomadas pela Comissão irão exercer impacto sobre toda a sociedade internacional. Isso ocorre porque toda expansão da plataforma continental de um Estado costeiro, além do limite das 200 milhas marítimas, tem como consequência a diminuição da Área, considerada patrimônio comum da humanidade.

Assim, a Comissão criada para examinar os pleitos estatais sobre as questões relacionadas com o estabelecimento dos limites exteriores da plataforma continental, ou seja, além do limite inicial das 200 milhas marítimas, sofre pressão de dois lados. De um lado, dos Estados costeiros que buscam maximizar seus pleitos e, de outro, dos Estados sem litoral e geograficamente desfavorecidos, que não contam com plataforma continental ou não têm possibilidade de expandi-la e que, por conseguinte, não têm interesse em um aumento das plataformas continentais dos Estados costeiros.

O objetivo principal deste artigo é, portanto, em, um primeiro momento, examinar a possibilidade prevista no artigo 76 da Convenção das Nações Unidas sobre o Direito do Mar (CNUDM) de extensão da plataforma continental além das 200 milhas marítimas, para, em um segundo momento, analisar os principais aspectos que levaram à criação da CLPC, seu atual funcionamento, o trabalho por ela desenvolvido até esse momento e, na parte final, observar os desafios que vem enfrentando para cumprir seus fins e que certamente serão incrementados nos próximos anos.

\section{Plataforma continental: definição e POSSIBILIDADE DE EXPANSÃO}

Uma das principais novidades da CNUDM consiste na nova definição jurídica da plataforma continental consagrada no artigo 76 do texto convencional, consideravelmente diferente da que constava na Convenção sobre a Plataforma Continental, que fora aprovada na I Conferência das Nações Unidas sobre o Direito do Mar (1958).

Segundo a Convenção sobre a Plataforma Continental de 1958, esta era conceituada como o "leito do mar e o subsolo das regiões submarinas [...] até uma profundidade de 200 metros ou, para além deste limite, até ao ponto onde a profundidade das águas superjacentes permita a exploração dos recursos naturais das ditas regiões" (artigo $1^{\circ}$ ).

A definição de plataforma continental consagrada nesta Convenção não foi baseada exclusivamente em características geológicas ou geomorfológicas. Além disso, tratava-se de um sistema claramente impreciso, complicado e virtualmente impraticável, já que envolvia, de um lado, uma profundidade específica das águas (200 metros) e, de outro, um critério indefinido de aproveitamento.

Já a definição de plataforma continental consagrada no artigo 76 da CNUDM tampouco é baseada de maneira exclusiva em características geológicas ou geomorfológicas. No entanto, utiliza-se de outros dois critérios para definir plataforma continental. Nos termos do artigo 76.1: "a plataforma continental de um Estado costeiro compreende o leito e o subsolo das áreas submarinas [...] em toda a extensão do prolongamento natural do seu território terrestre, até ao bordo exterior da margem continental ou até uma distância de 200 milhas marítimas". Ou seja, neste artigo 76.1 a CNUDM utilizou-se de dois critérios para fixar os limites da plataforma continental, o critério geomorfológico (margem continental) e o critério da distância (200 milhas marítimas). Ou, como resumem exemplarmente Robert Smith e George Taft, o parágrafo $1^{\circ}$ do artigo 76 “define a plataforma continental de uma maneira em que é cientificamente embasada, legalmente defensável e politicamente aceitável". ${ }^{1}$

De acordo com a publicação oficial da Divisão de Assuntos Oceânicos e Direito do Mar, órgão das Na-

1 SMITH, Robert; TAFT, George. Legal Aspects of the Continental Shelf. In: COOK, Peter J.; CARLETON, Chris M. Continental Shelf Limits: the scientific and legal interface. Oxford: Oxford University Press, 2000.p. 17-24. p. 17. Tradução do original: "defines the continental shelf in a manner which is scientifically based, legally defensible, and politically acceptable". 
ções Unidas (UN Division of Ocean Affairs and the Law of the Sea-DOALOS):

Tal como empregado pelo artigo 76, "massa terrestre" e "margem continental" são conceitos científicos geomorfológicos, enquanto "território terrestre" e "plataforma continental" são conceitos jurídicos. [...] O território terrestre é parte emersa enquanto a plataforma continentalé a parte submersa ou, como a definição coloca, o prolongamento natural do território terrestre. Entretanto, o conceito jurídico de território e de plataforma continental é definido tomando como referência os conceitos científicos de massa terrestre e margem continental. Em outras palavras, a combinação das duas definições dispõe que (i) o território do Estado costeiro se estende sob as águas; (ii) a plataforma continental constitui-se na extensão submersa do território terrestre do Estado; e (iii) o limite exterior dessa extensão é medida tomando como referência o prolongamento submerso da massa terrestre, isto é, a "margem continental". A margem continental é tão-somente um parâmetro, uma referência, da plataforma continental "jurídica". Dependendo de inúmeras circunstâncias geomorfológicas a plataforma continental "jurídica" pode ser maior ou menor que a margem continental. ${ }^{2}$

Dessa forma, o Estado costeiro tem duas opções: i) fixar sua plataforma continental até uma distância máxima de 200 milhas marítimas, contadas a partir das linhas de base, independentemente dos fatores geológicos ou geomorfológicos da mesma; ou, ii) poderá estender sua plataforma continental até o bordo exterior da margem continental, desde que este limite não exceda 350 milhas marítimas ou uma distância que não exceda 100 milhas marítimas da isóbara de 2.500 metros.

2 UNITED NATIONS. Division for Ocean Affairs and the Law of the Sea, Office of Legal Affairs. Training Manual for Delineation of the Outer Limits of the Continental Shelf beyond 200 nautical miles and for Preparation of Submissions to the Commission on the Limits of the Continental Shelf. New York: United Nations, 2006. p. I-18. Tradução do original: "As used in article 76, "land mass" and "continental margin" are scientific (geomorphological) concepts, whereas "land territory" and "continental shelf" are legal concepts. [...]The land territory is the emerged part whereas the continental shelf is the submerged or, as the definition puts it, the natural prolongation of the land territory. The legal concepts of territory and continental shelf, however, are defined with reference to the scientific concepts of land mass and continental margin. In other words, the two definitions combined declare that (i) the territory of a coastal State extends under water; (ii) the continental shelf constitutes the submerged prolongation of its land territory; and (iii) the outer limit of such prolongation is measured with reference to the submerged prolongation of the land mass, i.e., the "continental margin". The continental margin is just a yardstick, a reference, for the determination of the "legal" continental shelf. Depending on the various geomorphological circumstances the "legal" continental shelf can be wider or narrower that the continental margin." (grifos do original).
Na hipótese de o Estado costeiro utilizar-se do segundo critério, ou seja, expandir sua plataforma continental além do limite inicial das 200 milhas marítimas, os parágrafos 4 a 7 do artigo 76 fornecem "fórmulas" específicas e "restrições" para os fins de delineação da plataforma continental além das 200 milhas marítimas.

Para traçar esse limite exterior da plataforma continental, os Estados costeiros usam uma das duas fórmulas: unir, mediante linhas retas que não excedam 60 milhas marítimas do pé do talude continental, nesse caso, essa linha é a demarcação oficial $3 / 4$ além dessa linha estão os fundos marinhos $3 / 4$ e pode ser estendida até o limite máximo de 350 milhas marítimas dos quais se mede o mar territorial; ou, "100 milhas marítimas de isóbara de 2.500 metros, que é uma linha que une profundidades de 2.500 metros", isto é, pode ir além mesmo das 350 milhas marítimas. Os Estados podem se utilizar de quaisquer das duas medidas de opção para fazer a sua proposta de expansão à CLPC. A intenção é a de permitir que os Estados costeiros maximizem seus pedidos dentro dos parâmetros estabelecidos para o limite exterior da plataforma continental. ${ }^{3}$

Como se trata de um procedimento complexo, especialmente porque os Estados podem combinar diferentes elementos das fórmulas, criando, dessa maneira, uma combinação difícil de decifrar, os Estados decidiram criar um órgão técnico, a Comissão de Limites da Plataforma Continental (CLPC), com a missão principal de examinar os dados e outros elementos de informação apresentados pelos Estados costeiros sobre os limites exteriores da plataforma continental nas zonas em que tais limites se estenderem além das 200 milhas marítimas e formular recomendações "definitivas e obrigatórias", nos termos do parágrafo 8 do artigo 76.

\section{A Comissão de Limites da Plataforma Continental (CLPC)}

A Comissão de Limites da Plataforma Continental é um dos três órgãos criados pela CNUDM, os outros dois foram a Autoridade Internacional dos Fundos Marinhos e o Tribunal Internacional do Direito do Mar. O artigo 76 e o Anexo II da CNUDM tratam de seus

3 CAVNAR, Anna. Accountability and the Commission on the Limits of the Continental Shelf: deciding who owns the ocean floor. Cornell International Law Journal, v. 42, p. 397, 2009. 
principais aspectos. Trata-se de órgão técnico instituído para examinar os dados apresentados pelos Estados costeiros sobre os limites exteriores da plataforma continental, ou seja, sobre a plataforma continental além das 200 milhas marítimas.

\subsection{A CLPC: criação, mandato, composição e o prazo de 10 anos}

A ideia do estabelecimento de uma comissão técnica para analisar as submissões estatais sobre os limites exteriores da plataforma continental foi levantada pela primeira vez pelos Estados Unidos na terceira sessão de trabalhos (1975) da III Conferência das Nações Unidas sobre o Direito do Mar. Na sessão seguinte, também o Canadá e o Japão propuseram uma comissão nos mesmos moldes. ${ }^{4}$

A criação da CLPC não sofreu grande oposição dos grupos ou de Estados de maneira isolada. Isso porque havia o entendimento de que a fórmula para a definição da plataforma continental estipulada no artigo 76 da CNUDM tornava-a mais científica e técnica e os negociadores compreendiam a importância e o papel relevante que teria uma comissão para examinar os aspectos técnicos e científicos da plataforma continental estendida. ${ }^{5}$

A Comissão é composta por 21 membros, peritos em geologia, geofísica ou hidrografia, eleitos pelos Estados-partes da Convenção entre seus nacionais, "tendo na devida conta a necessidade de assegurar uma representação geográfica equitativa os quais prestarão serviços a título pessoal", eleitos para um mandato de cinco anos, que poderá ser renovado (artigo $2^{\circ}$, Anexo II).

A CLPC tem, entre suas funções:

\begin{abstract}
a) examinar os dados e outros elementos de informação apresentados pelos Estados costeiros sobre os limites exteriores da plataforma continental nas zonas em que tais limites se estenderem além de 200 milhas marítimas e formular recomendações de conformidade com o artigo 76 e a declaração de entendimento adotada em 29 de Agosto de 1980 pela Terceira Conferência das Nações Unidas sobre o Direito do Mar;

b) prestar assessoria científica e técnica, se o Estado costeiro interessado a solicitar, durante a preparação dos dados referidos na alínea a).
\end{abstract}

4 SUAREZ, Suzette V. The outer limits of the continental shelf: legal aspects of their establishment. Berlin: Springer, 2008. p. 76.

5 SUAREZ, Suzette V. The outer limits of the continental shelf: legal aspects of their establishment. Berlin: Springer, 2008. p. 78.
Dessa forma, quando um Estado costeiro tiver a intenção de expandir os limites da plataforma continental além das 200 milhas marítimas, nos termos previstos no artigo 76 da CNUDM, o Estado costeiro deverá apresentar as informações científicas e técnicas que apoiam seu pleito para a CLPC. Nos termos do artigo $4^{\circ}$ do Anexo II, o Estado costeiro tem um prazo de 10 anos seguintes à entrada em vigor da CNUDM para apresentar essas informações.

Em decorrência das dificuldades para o cumprimento dessa obrigação, já que o artigo 76 não ajudava os Estados costeiros na preparação técnica da submissão da proposta de expansão da plataforma continental, a Reunião dos Estados-partes da Convenção (States Parties to the United Nations Convention on the Law of the SeaSPLOS), adotou em 13 de maio de 1999, as Diretrizes Técnicas e Científicas (Scientific and Technical Guidelines) ${ }^{6}$. As Diretrizes Técnicas e Científicas são especialmente importantes porque a Convenção entrou em vigor internacionalmente em 16 de novembro de 1994 e a ausência até então de diretrizes técnicas era considerada com uma desvantagem para os Estados costeiros que já eram parte da CNUDM, que consideravam o documento técnico de importância crucial para os Estados que pretendiam fazer uma proposta de submissão. ${ }^{7}$

Posteriormente, o prazo de dez anos seguintes à entrada em vigor da Convenção - que ocorreria em 16 de novembro de 2004 - foi alterado por decisão dos Estados-partes da Convenção (SPLOS/72). Portanto, o prazo de dez anos passou a viger a partir data da aprovação das Diretrizes Técnicas e Científicas, em 13 de maio de 1999, encerrando-se, em 13 de maio de 2009, para aqueles Estados que já haviam ratificado a CNUDM na data de entrada em vigor internacional do tratado. ${ }^{8}$

Uma vez mais, frente a um desejo de alguns Estados costeiros, especialmente de Estados em desenvol-

6 CLCS/11.13 May 1999. Scientific and Technical Guidelines of the Commission on the Limits of the Continental Shelf. Disponível em: <http:// daccess-dds-ny.un.org/doc/UNDOC/GEN/N99/171/08/IMG/ N9917108.pdf?OpenElement>. Acesso em: 25 apr. 2015.

7 CARLETON, Chris. Article 76 of the UN Convention on the Law of the Sea - implementation problems from the technical perspective. The International Journal of Marine and Coastal Law, v. 21, n. 3, p. 288, 2006.

8 Conforme visto no Capítulo 1, item 1.5.1.3, essa decisão foi tomada pela Reunião dos Estados-partes da CNUDM. SPLOS/72, 29 May 2001. Decision regarding the date of commencement of the ten-year period for making submissions to the Commission on the Limits of the Continental Shelf set out in article 4 of Annex II to the United Nations Convention on the Law of the Sea. 
vimento, no sentido de que o prazo de dez anos fosse novamente estendido, a Reunião dos Estados-partes decidiu que esse prazo reputar-se-ia observado com a transmissão ao Secretário-Geral da ONU de "informação preliminar indicativa dos limites exteriores da plataforma continental além das 200 milhas marítimas e uma descrição do estágio de preparação e da data prevista para o envio da proposta" (SPLOS/183) ${ }^{9}$. Contudo, essa informação preliminar apresentada não será examinada pela CLPC, e, tampouco, prejudica uma futura submissão completa por parte do Estado costeiro.

Como salienta Bjorn Kunoy, ainda que a permissão prevista no documento SPLOS/183 se referisse particularmente aos Estados em desenvolvimento em cumprir o disposto no artigo $4^{\circ}$ do Anexo II da CNUDM, bem como a decisão que consta no parágrafo 'a' do documento SPLOS $/ 72^{10}$, alguns Estados costeiros desenvolvidos, casos da Espanha e França, aproveitaram a brecha e também apresentaram apenas informações preliminares e parciais sobre os limites exteriores da plataforma continental. ${ }^{11}$

$\mathrm{O}$ artigo $4^{\circ}$ do Anexo II é silente sobre as eventuais consequências da não apresentação à Comissão da proposta de expansão da plataforma continental dentro desse prazo de dez anos. Podem-se vislumbrar duas hi-

9 SPLOS/183, 20 June 2008. Decision regarding the workload of the Commission on the Limits of the Continental Shelf and the ability of States, particularly developing States, to fulfil the requirements of article 4 of annex II to the United Nations Convention on the Law of the Sea, as well as the decision contained in SPLOS/72, paragraph (a). Tradução do original: "[...] preliminary information indicative of the outer limits of the continental shelf beyond 200 nautical miles and a description of the status of preparation and intended date of making a submission". 10 SPLOS/183, 20 June 2008. O parágrafo mencionado por Kunoy tem a seguinte redação: "Recognizing that some coastal States, in particular developing countries, including small island developing States, continue to face particular challenges in submitting information to the Commission in accordance with article 76 of the Convention and article 4 of annex II to the Convention, as well as the decision contained in SPLOS/72, paragraph (a), due to a lack of financial and technical resources and relevant capacity and expertise, or other similar constraints" (grifo nosso).

11 KUNOY, Bjorn. Disputed Areas and the 10-Year Time Frame: a Legal Lacuna? Ocean Development \& International Law, v. 41, p. 115, 2010. Veja-se, por exemplo, os termos da proposta parcial da Espanha sobre os limites exteriores da plataforma continental na parte oeste das ilhas Canárias: "De acuerdo con la disposición de SPLOS/183 del 20 Junio de 2008, España puede presentar antes del 13 Mayo de 2009, únicamente información preliminar indicativa de los límites exteriores de la plataforma continental más allá de las 200 millas marinas y una descripción del estado de preparación y de la fecha prevista de envío de la presentación, para cualquiera de las áreas parciales que considere oportuna". póteses: a primeira seria que o Estado costeiro perderia o direito de apresentar proposta de submissão à CLPC; a segunda seria de que a Comissão não teria a obrigação de aceitar uma proposta depois do prazo limite. ${ }^{12}$

Contudo são apenas conjecturas. Não há qualquer tipo de penalidade caso o Estado costeiro não consiga apresentar sua submissão à CLPC no prazo de dez anos. A CNUDM não traz previsão nesse sentido e não há, tampouco, contexto político ou jurídico que autorize uma conclusão em contrário, o que certamente seria evidenciado explicitamente no texto final da Convenção.

Durante a Reunião dos Estados-partes da CNUDM, realizada em junho de 2001, ficou registrado que:

\begin{abstract}
Algumas delegações assinalaram que a Convenção não estipulava nenhuma consequência jurídica para o caso de que um Estado não fizesse uma apresentação à Comissão. Várias delegações assinalaram o princípio de que os direitos dos Estados costeiros sobre sua plataforma continental eram inerentes, e que o incumprimento do prazo de 10 anos especificado no artigo $4^{\circ}$ do Anexo II não afetaria negativamente os direitos que não dependiam da ocupação, real ou fictícia, bem como de nenhuma reclamação expressa, como consta do parágrafo $3^{\circ}$ do artigo 77 da Convenção..$^{13}$
\end{abstract}

Todavia, os Estados devem considerar o prazo de dez anos e medir esforços para que tal limite seja respeitado ${ }^{14}$. Nesse sentido, é interessante considerar o caso da Federação Russa: em 2001, o Estado russo foi o primeiro a fazer uma submissão à uma plataforma continental estendida à CPLC. A resposta inicial da Comissão, no ano seguinte, não atendeu à integralidade do pedido russo. De acordo com os parágrafos 38-41 das recomendações encaminhadas à Federação Russa, a

12 ELFERINK, Alex G. Oude. Article 76 of the LOSC on the definition of the Continental Shelf: questions concerning its interpretation from a legal perspective. The International Journal of Marine and Coastal Law, v. 21, n. 3, p. 279, 2006.

13 SPLOS/73, 14 June 2001. Report of the Eleventh Meeting of State Parties. Tradução do original: "Some delegations pointed out that there was no legal consequence stipulated by the Convention if a State did not make a submission to the Commission. Several delegations underscored the principle that the rights of the coastal State over its continental shelf were inherent, and that non-compliance with the 10-year time period specified in article 4 of annex II would not adversely affect those rights, which did not depend on occupation, effective or notional, or any express proclamation, as stated in article 77, paragraph 3, of the Convention".

14 TAFT, George. The United Nations Convention on the Law of the Sea: The Commission on the Limits of the Continental Shelf - a Force for Enhancing Stability in the Oceans (or Not). Ocean Yearbook, v. 24, p. 162, 2010. 
CLPC expressava que não havia reservas à proposta de extensão da plataforma continental no mar de Bering e no mar de Barents. Contudo, no tocante ao mar de Okhotsk, a Comissão sugeriu que fosse realizada uma proposta parcial adicional, acompanhada de esforços para solucionar questões jurisdicionais com o Japão. $\mathrm{Na}$ parte central do Ártico, a Comissão recomendou uma proposta revista. Como resultado dessa manifestação da CLPC, a Federação Russa passou, a partir de 2003, a realizar estudos adicionais sobre a plataforma continental, especialmente no Ártico. ${ }^{15}$

Tomando-se como referência o prazo de dez anos previsto no artigo $4^{\circ}$ do Anexo II, imaginava-se que o "prazo razoável" mencionado no artigo $8^{\circ}$ do Anexo II não poderia superar esses dez anos ${ }^{16}$. No entanto, somente em 28 de fevereiro de 2013 a Federação Russa apresentou uma submissão parcial revista no tocante ao mar de Okhotsk. E, mesmo superado o prazo de dez anos, a Comissão aceitou as informações apresentadas pelo país.

\subsection{As recomendações "definitivas e obrigatórias"}

Um dos pontos mais controversos sobre a atuação da Comissão é o que trata sobre o alcance de suas recomendações. Como frisado acima, uma das missões da CLPC é formular recomendações em conformidade com o artigo 76. Essa função conduz a um dos pontos mais importantes e mais controversos deste artigo, que é o parágrafo $8^{\circ}$, visto que, na parte final desse dispositivo, consta que a

[...] Comissão fará recomendações aos Estados costeiros sobre questões relacionadas com o estabelecimento dos limites exteriores da sua plataforma continental. Os limites da plataforma continental estabelecidos pelo Estado costeiro com base nessas recomendações serão definitivos e obrigatórios.

A questão sobre o real alcance das recomendações da CLPC foi tema de debate ainda nos primeiros anos de negociações da III Conferência. Por exemplo, a União Soviética sugeriu que ao invés de se utilizar a palavra "decisão", fosse utilizado o termo "recomendação",

15 SILVA, Alexandre Pereira da. A Rússia avança no Ártico. Boletim Meridiano 47, v. 15, n. 142, p. 122, mar./abr. 2014.

16 MACNAB, Ron; PARSON, Lindsay. Continental Shelf Submissions: the record to date. The International Journal of Marine and Coastal Law, v. 21, n. 3, p. 311, 2006. para referir-se às manifestações futuras da Comissão. Outras delegações, percebendo a mudança de poder da Comissão para o Estado costeiro tentaram fortalecer as consequências jurídicas das recomendações da Comissão como, por exemplo, a proposta informal de Cingapura de que a frase "tendo em conta essas recomendações" ("taking into account these recommendations") devesse ser entendida como "deve estar de acordo com essas recomendações" ("shall be in accordance with these recommendations"). Já próximo da parte final dos trabalhos da III Conferência, a expressão "tendo em conta essas recomendações", foi substituída por "com base nessas recomendações" ("on the basis of these recommendations"), mas associada à expressão "definitivos e obrigatórios" ("final and binding"). ${ }^{17}$

Nessa linha, de um lado, a expressão "tendo em conta essas recomendações" deixava ampla margem de manobra para os Estados costeiros e deixava implícita a ideia de que o Estado costeiro poderia simplesmente estabelecer seus limites exteriores "tendo em conta essas recomendações" da Comissão, mas poderia, da mesma maneira, rejeitar aspectos significativos das recomendações da CLPC. Por outro lado, a expressão adotada na versão final do artigo 76.8, diz muito pouco sobre as reais implicações da expressão "com base nessas recomendações". ${ }^{18}$

$\mathrm{Na}$ hipótese de que um Estado costeiro venha discordar das recomendações, deve apresentar à Comissão "dentro de um razoável uma proposta revista ou uma nova proposta" (artigo $8^{\circ}$, Anexo II) ${ }^{19}$. Decorrente dessa previsão legal, pode se criar uma interminável situação de "ping-pong", ou seja, submissão por parte do Estado costeiro, depois recomendações da Comissão, nova submissão por parte do Estado costeiro, novas recomendações da Comissão etc. Mesmo que o Estado costeiro atue de boa-fé e a Comissão eventualmente

17 SUAREZ, Suzette V. The outer limits of the continental shelf: legal aspects of their establishment. Berlin: Springer, 2008. p. 213-214.

18 ELFERINK, Alex G. Oude. Article 76 of the LOSC on the definition of the Continental Shelf: questions concerning its interpretation from a legal perspective. The International Journal of Marine and Coastal Law, v. 21, n. 3, p. 280, 2006.

19 Por exemplo, essa é a situação atual do pleito brasileiro a uma plataforma continental estendida. O Brasil foi o segundo Estado a realizar uma submissão à CLPC em maio de 2004 (CLCS/42). No entanto, do total da área reivindicada pelo Brasil, a Comissão não concordou com cerca de $190.000 \mathrm{~km}^{2}$, ou seja, cerca de $20 \%$ da área estendida além das 200 milhas marítimas (CLCS/54, 4 April 2007). Recentemente, o Brasil encaminhou à CLPC (10 de abril de 2015) uma submissão parcial revista sobre a região sul do Brasil. 
consiga alcançar um consenso, é importante notar que não há qualquer previsão legal que ponha fim a esse processo de "ping-pong". ${ }^{20}$

Assim, qual seria o verdadeiro papel da CLPC na delineação dos limites exteriores da plataforma continental? Para Ted McDorman, "uma certeza é que é o Estado costeiro, e não a Comissão, quem tem a capacidade jurídica de fixar os limites exteriores da margem continental do Estado" 21 . Nesse mesmo sentido, Alex Oude Elferink afirma que à "Comissão não foi dado o poder de indicar se o Estado costeiro atuou com bases nas suas recomendações. Outros Estados podem levantar questões com o Estado costeiro". ${ }^{22}$

Na mesma linha, também estão Smith e Taft:

A Comissão não estabelece os limites do bordo
exterior da plataforma continental; isto continua
sendo função do Estado costeiro, após a
apresentação de informações pertinentes à definição
dos limites exteriores e recomendações feitas pela
Comissão. Caso as recomendações da Comissão
sejam aceitas pelo Estado costeiro, este estabelecerá
os limites exteriores baseado nas recomendações da
Comissão; estes limites serão finais e obrigatórios.

Portanto, o correto entendimento das recomendações "definitivas e obrigatórias" da CLPC é que essas devem ser compreendidas da seguinte maneira: são re-

20 MCDORMAN, Ted L. The role of the Commission on the Limits of the Continental Shelf: a technical body in a political world. The International Journal of Marine and Coastal Law, v. 17, n. 3, p. 306, 2002.

21 MCDORMAN, Ted L. The role of the Commission on the Limits of the Continental Shelf: a technical body in a political world. The International Journal of Marine and Coastal Law, v. 17, n. 3, p. 306, 2002. Tradução do original: "[...] one certainty is that it is the coastal state, not the Commission, which has the legal capacity to set the state's outer limit of the continental margin".

22 ELFERINK, Alex G. Oude. Article 76 of the LOSC on the definition of the Continental Shelf: questions concerning its interpretation from a legal perspective. The International Journal of Marine and Coastal Law, v. 21, n. 3, p. 281, 2006. Tradução do original: "The Commission has not been given the power to indicate if a coastal state has acted on the basis of its recommendations. Other states can raise this matter with a costal state".

23 SMITH, Robert; TAFT, George. Legal Aspects of the Continental Shelf. In: COOK, Peter J.; CARLETON, Chris M. Continental Shelf Limits: the scientific and legal interface. Oxford: Oxford University Press, 2000. p. 17-24. p. 20. Tradução do original: “The Commission does not establish the outer limit of the continental shelf; that remains the function of the coastal State following submission of information pertaining to the definition of the outer limit and the recommendation by the Commission. If the Commission's recommendations are acceptable to the coastal State, then the State may establish the outer limits in a manner based on the Commission's recommendations; those limits are the final and binding". comendações. Tão-somente recomendações, que podem servir ao Estado costeiro para definir os limites exteriores da plataforma continental estendida além das 200 milhas marítimas, mas que não impedem que esse mesmo Estado costeiro fixe limites distintos, dentro do estipulado no artigo 76.5. Nessa hipótese, no entanto, outros Estados poderão contestar esses limites, já que o procedimento previsto no artigo 76 não teria sido plenamente obedecido. ${ }^{24}$

\section{Os desafios atuais da Comissão}

A CLPC tem enfrentado importantes desafios para cumprir suas funções, entre esses destacam-se: o volume de trabalho, o financiamento para o funcionamento da Comissão e a atuação dos terceiros Estados nas submissões dos Estados costeiros.

\subsection{O volume de trabalho}

O maior desafio que a Comissão já vem enfrentando e que certamente será agravado nos próximos anos versa sobre o volume de trabalho a ser analisado por seus membros. Esse acúmulo de trabalho da CLPC dá-se porque o número de Estados costeiros que apresentaram informações à Comissão é muito superior ao previsto durante os trabalhos da III Conferência das Nações Unidas.

Conforme previsto no $5^{\circ}$ do Anexo II da CNUDM, “a não ser que a Comissão decida de outro modo, deve funcionar por intermédio de subcomissões compostas de sete membros, designados de forma equilibrada tomando em conta os elementos específicos de cada proposta encaminhada pelo Estado costeiro". Em razão dos resultados da Reunião dos Estados-partes (SPLOS/144 e SPLOS/148), a Comissão decidiu na sua $18^{a}$ sessão (CLCS/52), de outubro de 2006, que:

Somente três subcomissões funcionarão
simultaneamente enquanto consideram as
submissões. As submissões devem ser colocadas em
ordem em que são recebidas. A submissão seguinte
deve ser apreciada por uma subcomissão somente
depois de uma das três subcomissões de trabalho
apresentar suas recomendações à Comissão.

24 SILVA, Alexandre Pereira da. O novo pleito brasileiro no mar: a plataforma continental estendida e o Projeto Amazônia Azul. Revista Brasileira de Politica Internacional, v. 56, n. 1, p. 113-114, 2013.

25 Esse ponto foi ratificado também no Regulamento da CLPC (CLCS/40/Rev. 1), adotado em abril de 2008, no artigo 51, em espe- 
Em um estudo realizado pela Comissão em setembro de 2009, quando haviam sido recebidas 51 submissões, a expectativa era de que os trabalhos da CLPC se estenderiam até 2030. Mas, nesse cenário não eram consideradas a apresentação de novas propostas e submissões revistas por parte de Estados costeiros que já tinham apresentados submissões, propostas de Estados costeiros que ainda tinham prazo para apresentá-las, submissões em áreas disputadas, submissões de novos Estados-partes na CNUDM e submissões decorrentes das então 44 Informações Preliminares apresentadas. ${ }^{26}$

Em abril de 2015, mais de cinco anos passados desse estudo da Comissão, os números do volume de trabalho são ainda mais expressivos: são 77 submissões apresentadas - não incluídas as propostas revistas-, além de 45 Informações Preliminares.

Várias delegações têm expressado preocupações com a carga de trabalho da Comissão e destacado a necessidade de seguir melhorando os métodos de trabalho, de forma a assegurar que as submissões sejam examinadas em um prazo razoável. Foi lembrado também que o número de Estados costeiros que, segundo o inicialmente previsto, formularam submissões era quatro vezes superior ao número estimado quando se redigiu o artigo $5^{\circ}$ do Anexo II da CNUDM (SPLOS/263).

A título de exemplo, o caso da nova submissão parcial da Dinamarca, apresentada em dezembro de 2014, uma das últimas submetidas à CLPC até o momento, trata de uma reivindicação de aproximadamente 900.000 quilômetros quadrados de plataforma continental estendida somente no Ártico, na região da plataforma continental no norte da Groenlândia, cuja área é vinte vezes maior do que a própria Dinamarca. Em razão da grande quantidade de reivindicações pendentes a serem examinadas pela CLPC, é provável que esse pleito dinamarquês leve de dez a quinze anos para ser avaliado. ${ }^{27}$

cial no parágrafo $4^{\circ}$. Tradução do original: "Only three subcommissions shall function simultaneously while considering submissions. The submissions shall be queued in the order they are received. The submission next in line shall be taken for consideration by a subcommission only after one of the three working subcommissions presents its recommendations to the Commission".

26 UNITED NATIONS. Presentation to burean MSP. Disponível em: <http://www.un.org /Depts/los/clcs_new/workload / presentation_to_bureau_msp_2009.pdf>. Acesso em: 25 abr. 2015.

27 BARENTS OBSERVER. Denmark claims North Pole. Disponível em: <http://barentsobserver.com/en/arctic/2014/12/denmarkclaims-north-pole-15-12>. Acesso em: 25 abr. 2015.

\subsection{O financiamento da Comissão}

Outro desafio, diretamente ligado à questão do volume de trabalho da CLPC, é o tema do financiamento da Comissão e que se reflete no próprio funcionamento do órgão.

Ainda que prestem "serviços a título pessoal", as despesas dos membros da Comissão são cobertas pelos Estados que patrocinaram a indicação dos membros e não pelas Nações Unidas. É o que dispõe o parágrafo $5^{\circ}$ do artigo $2^{\circ}$ do Anexo II da CNUDM: "O Estado-Parte que tiver apresentado a candidatura de um membro da Comissão custeará as despesas do mesmo enquanto prestar serviço na Comissão". Esse dispositivo é repetido no artigo $9^{\circ}$ do Regulamento da Comissão, aprovado em abril de 2008 (CLCS/40/Rev. 1).

Essa circunstância gera algumas situações inusitadas. Por exemplo, segundo o documento CLCS/85, de 24 de setembro de 2014, que trata das atividades desenvolvidas pela Comissão no último período de sessões - 21 de julho a 5 de setembro de 2014 ( $35^{\circ}$ período de sessões) — dois de seus membros não puderam assistir a todas as sessões de trabalhos "por falta de apoio financeiro". ${ }^{28}$

A Reunião dos Estados-partes da CNUDM considerou, recentemente, que esse tipo de apoio financeiro impede que Estados em desenvolvimento e pequenos países insulares se vejam possibilitados de designar membros para a Comissão. Nesse sentido, foi lembrado que o requisito de dez anos para apresentação de uma proposta à CLPC foi flexibilizado pela Reunião dos Estados-partes no passado para enfrentar certos problemas relativos à aplicação da CNUDM e que esse tipo de flexibilização poderia ser novamente utilizado nesse caso da obrigação financeira (SPLOS/263).

Outra questão que preocupa os membros da Comissão refere-se à questão do seguro de saúde durante as reuniões de trabalho em Nova Iorque. De acordo com

28 Vide CLCS/85, 24 September 2014, Progress of Work in the Commission on the Limits of the Continental Shelf: "[...] Mr. Jaoshvili attended the session from 2 to 5 September 2014, indicating that he had been unable to attend the entire session owing to a lack of adequate financial support. Mr. Uścinowicz attended the session from 11 August to 5 September, indicating that he had not been able to attend the earlier part of the session owing to a lack of adequate financial support". Os dois membros da Comissão mencionados, são da Geórgia e da Polônia, respectivamente. Essa situação de falta de apoio financeiro aos membros para participarem dos trabalhos da Comissão é frequentemente mencionado nos documentos da CLPC. 
a Resolução da Assembleia Geral das Nações Unidas 68/70, de 9 de dezembro de 2013, a Comissão solicitou que o Secretário-Geral da ONU examine possíveis opções para oferecer a cobertura de um seguro de saúde aos membros da Comissão procedentes de Estados em desenvolvimento. Esse ponto foi reafirmado na Reunião dos Estados-partes da CNUDM, de junho de 2014:

\begin{abstract}
Reitera a obrigação nos termos da Convenção que os Estados cujos especialistas estejam servindo à Comissão de custear os gastos desses especialistas que tenham indicado enquanto desempenham funções relacionadas com a Comissão, incluindo a prestação de assistência médica, e insta os Estados a envidar todos os esforços para assegurar a plena participação desses especialistas no trabalho da Comissão, incluindo as reuniões das subcomissões, de acordo com a Convenção. ${ }^{29}$
\end{abstract}

Essa situação muito possivelmente será agravada no futuro, porque em virtude da decisão da $21^{a}$ Reunião dos Estados-partes relativa ao volume de trabalho da Comissão (SPLOS/229), foi incluída a solicitação para que a Comissão examine a possibilidade de reunir-se em Nova Iorque por até 26 semanas. Atualmente, a CLPC reúne-se em três períodos de sessões de sete semanas, cada uma, incluídas sessões plenárias, em um total de 21 semanas de reuniões da Comissão e suas subcomissões. ${ }^{30}$

A fim de enfrentar os frequentes problemas financeiros, o presidente da Comissão solicitou, em maio de 1999, que os Estados-partes considerassem a possibilidade de criação de um fundo fiduciário (trust fund) para financiar a participação dos membros dos países em desenvolvimento nos trabalhos da Comissão. A criação do fundo fiduciário voluntário foi aprovada em outubro de 2000 durante os trabalhos da 55 a Assembleia Geral das Nações Unidas. O fundo é atualmente administrado pela Divisão de Assuntos Oceânicos e Direito do Mar, Escritório de Assuntos Jurídicos (DOALOS).

De acordo com o último relatório sobre os progressos dos trabalhos da Comissão (CLCS/85), de 24 de setembro de 2014, durante as duas últimas reuniões de

29 Tradução do original: "Reiterates the obligation of States under the Convention whose experts are serving on the Commission to defray the expenses of the experts they have nominated while in performance of Commission duties, including the provision of medical coverage, and urges these States to do their utmost to ensure the full participation of those experts in the work of the Commission, including the meetings of subcommissions, in accordance with the Convention".

30 SPLOS/229, 16 June 2011, Decision regarding the workload of the Commission on the Limits of the Continental Shelf. trabalhos $\left(34^{\mathrm{a}}\right.$ e $\left.35^{\mathrm{a}}\right)$, o fundo fiduciário proporcionou assistência financeira de aproximadamente US $\$ 170.000$ em cada uma das reuniões para oito membros de Estados em desenvolvimento. Nos termos do relatório, em junho de 2014, o fundo fiduciário tinha um saldo aproximado de US\$670.000. ${ }^{31}$

\subsection{A Comissão e a intervenção de terceiros Estados}

Outro importante desafio que a Comissão vem enfrentando refere-se à apresentação de notificação de terceiros Estados às submissões de Estados costeiros.

O artigo 83 da CNUDM dispõe obrigação conjunta tanto para o Estado costeiro que faz a submissão como para os terceiros Estados envolvidos no processo na CLPC. O artigo 83.1 coloca que "a delimitação da plataforma continental entre Estados com costas adjacentes ou situadas frente a frente deve ser feita por acordo, de conformidade com o direito internacional". O artigo 83.3 complementa ao dispor que "enquanto não se chegar a um acordo conforme o previsto no parágrafo $1^{\circ}$, os Estados interessados [...] nada devem fazer que possa comprometer ou entravar a conclusão do acordo definitivo".

Quanto ao papel da Comissão, quando houver disputas entre Estados sobre a delimitação da plataforma continental o artigo $9^{\circ}$ do Anexo II coloca que "as decisões da Comissão não devem prejudicar os assuntos relacionados com a delimitação entre Estados com costas adjacentes ou situadas frente a frente" ${ }^{32}$. Para muitos juristas, esse dispositivo limita o papel da CLPC de fazer recomendações e a coloca em uma posição passiva por dois motivos: i) a Comissão não exerce função em determinar ou influenciar negociações sobre os limites da plataforma continental entre Estados quando há so-

31 Além desse fundo fiduciário, existe também um outro fundo fiduciário no âmbito da Comissão que foi criado para auxiliar os Estados em desenvolvimento, particularmente os Estados menos desenvolvidos e os pequenos Estados insulares em desenvolvimento, na preparação das submissões à Comissão e no cumprimento do disposto no artigo 76 da CNUDM. Também segundo esse relatório (CLCS/85), esse fundo fiduciário, em julho de 2014, tinha um saldo de aproximadamente US\$1.306.000.

32 Esse dispositivo é repetido no artigo 46.2 do Regulamento da Comissão e colocado de maneira ligeiramente diferente no artigo 76.10 da CNUDM: "As disposições do presente artigo não prejudicam a questão da delimitação da plataforma continental entre Estados com costas adjacentes ou situadas frente a frente". 
breposição de pedidos sobre plataformas continentais estendidas; e, ii) a Comissão não deve se envolver em assuntos referentes à determinação dos limites exteriores da plataforma continental estendida de um Estado costeiro quando exista uma disputa com outro Estado sobre tal limite. ${ }^{33}$

Se um Estado costeiro toma a iniciativa de informar à Comissão sobre uma disputa de limites envolvendo sua submissão, aplica-se o Anexo I do Regulamento da CLPC conjuntamente com o artigo 46 desse mesmo Regulamento. Nos termos do parágrafo $1^{\circ}$ desse dispositivo, os Estados envolvidos em controvérsias que surjam a respeito da delimitação da plataforma continental não estão privados do direito de apresentar suas submissões à Comissão. Nessas circunstâncias, a Comissão bem como o Estado que apresentou a submissão deve seguir o previsto no Anexo I do Regulamento da CLPC. Nos termos do parágrafo $1^{\circ}$ do Anexo I: "A Comissão reconhece que a competência sobre as questões relativas às controvérsias que surjam em relação ao estabelecimento dos limites exteriores da plataforma continental cabe aos Estados".

Esse dispositivo, portanto, reconhece o direito exclusivo dos Estados 3/4 tanto o que apresentou a submissão como os terceiros Estados 3/4 de decidirem per si se existe a disputa e o direito de solucionarem a controvérsia entre eles.

Já o parágrafo $2^{\circ}$ do Anexo I do Regulamento dispõe que, nos casos em que exista uma controvérsia com respeito à delimitação da plataforma continental entre Estados adjacentes ou outras controvérsias territoriais ou marítimas pendentes, a Comissão será informada da controvérsia pelo Estado costeiro que fez a submissão. Enquanto isso, a Comissão receberá garantias que, na medida do possível, a submissão não prejudicará questões relativas à fixação dos limites entre os Estados. ${ }^{34}$

$\mathrm{Na}$ hipótese de um Estado costeiro não cumprir a mencionada obrigação de informar à Comissão a respeito da controvérsia com outros Estados, a Comissão tem que ser informada da disputa pelos terceiros Es-

33 GAU, Michael Sheng-Ti. Third Party Intervention in the Commission on the Limits of the Continental Shelf Regarding a Submission Involving a Dispute. Ocean Development \& International Law, v. 40, p. 63, 2009.

34 GAU, Michael Sheng-Ti. Third Party Intervention in the Commission on the Limits of the Continental Shelf Regarding a Submission Involving a Dispute. Ocean Development \& International Law, v. 40, p. 64, 2009. tados. Nesse caso, os terceiros Estados devem intervir por meio de notificações dirigidas à Comissão no sentido de informar a CLPC da controvérsia. Contudo, isso não impede que o terceiro Estado esteja impedido de enviar uma notificação quando o Estado que apresentou a submissão cumpriu sua obrigação de informar sobre a disputa.

Portanto, em caso de disputa territorial ou marítima: "a Comissão não considerará nem qualificará uma submissão apresentada por qualquer dos Estados envolvidos na disputa" (parágrafo 5(a) do Anexo I do Regulamento). Contudo, na parte final desse dispositivo: "a Comissão poderá considerará uma ou mais submissões em áreas sob disputa com o consentimento prévio de todos Estados que estejam envolvidos nesta controvérsia". ${ }^{35}$

Vejam-se as duas situações possíveis previstas no parágrafo 5(a) do Anexo I do Regulamento da Comissão.

\section{A) Apresentação de notificação}

$\mathrm{Na}$ hipótese de apresentação de uma notificação, seguem-se as regras inscritas no artigo 50 do Regulamento da Comissão:

O Secretário-Geral notificará prontamente, por intermédio dos canais apropriados, a Comissão e os Estados-membros das Nações Unidas, incluídos os Estados-partes da Convenção, o recebimento da apresentação, e tornará público o resumo, incluídas todas as cartas e coordenadas mencionadas no parágrafo 9.1.4 das Diretrizes e contidas no respectivo resumo, uma vez concluída a tradução do resumo mencionado no artigo 47 , parágrafo $3^{\circ}{ }^{36}$

E no artigo 51.1 do Regulamento da Comissão:

Após o recebimento da submissão pelo Secretário-
Geral, o exame da submissão deverá ser incluído
na agenda provisória da próxima reunião ordinária
da Comissão preparada nos termos do artigo $5^{\circ}$
e do parágrafo $2^{\circ}$ do Anexo III, desde que essa
sessão, quando convocada em conformidade com

35 Tradução do original: "[...] the Commission shall not consider and qualify a submission made by any of the States concerned in the dispute $[\ldots]$ the Commission may consider one or more submissions in the areas under dispute with prior consent given by all States that are parties to such a dispute".

36 Tradução do original: "The Secretary-General shall, through the appropriate channels, promptly notify the Commission and all States Members of the United Nations, including States Parties to the Convention, of the receipt of the submission, and make public the executive summary including all charts and coordinates referred to in paragraph 9.1.4 of the Guidelines and contained in that summary, upon completion of the translation of the executive summary referred to in rule 47 , paragraph 3". 
o Artigo $2^{\circ}$, seja realizada não antes de três meses após a data em que o Secretário-Geral publique o resumo, incluídas todas as cartas e coordenadas mencionadas no artigo $50.3^{37}$

Dessa forma, e com base nesses dois dispositivos, o momento para que o terceiro Estado envie a notificação é entre a manifestação de recebimento pelo Secretário-Geral das Nações Unidas e o exame da submissão pela Comissão. Entre esses dois momentos, há, pelo menos, três meses para que o terceiro Estado tome a iniciativa de enviar a notificação. ${ }^{38}$

A apresentação de notificação por parte de terceiros Estados pode ser considerada como frequente. Entre os diversos casos, vale uma menção aos dois casos analisados abaixo:

i) no pleito da Federação Russa (2001), cinco Estados enviaram notificações, sendo que três não eram partes da CNUDM (Canadá, Dinamarca ${ }^{39}$ e Estados Unidos), além de Japão e Noruega.

Tanto o Canadá como a Dinamarca manifestaram-se no sentido de não terem condições de formar uma opinião sobre o pleito russo e por isso não estavam em posição de determinar se tinham preocupações com a submissão. Contudo, isso não implicava qualquer tipo de concordância ou aquiescência com a submissão da Federação Russa. ${ }^{40}$

37 Tradução do original: "Upon receipt of a submission by the Secretary-General, the consideration of that submission shall be included in the provisional agenda of the next ordinary session of the Commission prepared in accordance with rule 5 and paragraph 2 of annex III, provided that that session, as convened in accordance with rule 2 , is held not earlier than three months after the date of the publication by the Secretary-General of the executive summary including all charts and coordinates referred to in rule 50".

38 GAU, Michael Sheng-Ti. Third Party Intervention in the Commission on the Limits of the Continental Shelf Regarding a Submission Involving a Dispute. Ocean Development \& International Law, v. 40, p. 65, 2009.

39 Canadá e Dinamarca posteriormente depositaram seus instrumentos de ratificação. O Canadá em 7 de novembro de 2003 e a Dinamarca em 16 de novembro de 2004. Os Estados Unidos ainda não são parte da CNUDM.

40 "The Permanent Mission of Canada to the United Nations $[\ldots]$ is not in position to determine whether it agrees with the Russian Federation's Arctic continental shelf submission without the provision of further supporting data to analyse and that Canada's inability to comment at this point should not be interpreted as either agreement or acquiescence by Canada to the Russian Federation's submission". CANADA. Notification regarding the submission made by the Russian Federation to the Commission on the Limits of the Continental Shelf. 26 February 2002. Disponível em: <http://www.un.org/depts/los/ clcs_new/submissions_files/rus01/CLCS_01_2001_LOS_CANtext.pdf>. Acesso em: 25 abr. 2015. "Denmark is not able to form an opinion on the Russian submission. A qualified assessment would
Já a notificação enviada pela representação permanente norueguesa nas Nações Unidas registrou seu desacordo com a submissão russa com base no artigo 51 do Regulamento da Comissão:

A delimitação da plataforma continental entre a Noruega e a Federação Russa ainda não foi resolvida e é objeto de consultas em curso. A questão sobre a delimitação não resolvida no mar de Barents portanto deve ser considerada como uma "disputa marítima" para os propósitos do artigo 5(a) do Anexo I do Regulamento da Comissão. ${ }^{41}$

As notificações do Japão e dos Estados Unidos foram no sentido de desafiar a submissão da Federação Russa. Os norte-americanos registraram que: "acreditam que a submissão tenha grandes falhas no que se refere à plataforma continental no Ártico". Além disso, a notificação dos Estados Unidos tecia comentários específicos sobre as formações geológicas submarinas árticas de Alpha-Mendeleev e Lomonosov, finalizando no entendimento de que: "A submissão da Federação Russa é particularmente complexa e deve ser considerada de maneira deliberada". ${ }^{42}$

A notificação do Japão foi ainda mais veemente, apresentando em anexo um mapa e coordenadas geográficas, para rejeitar o exame pela Comissão de quatro ilhas (Etorofu, Kunashiri, Shikotan e Habomai), incluídas no pleito russo que criavam uma zona econômica exclusiva e plataforma continental com base em ocupação de território japonês desde o término da Segunda

require more specific data. Such absence of opinion at this moment does not imply Denmark's agreement or acquiescence to the Russian Federation's submission". DENMARK. Notification regarding the submission made by the Russian Federation to the Commission on the Limits of the Continental Shelf. 26 February 2002. Disponivel em: <http:// www.un.org/depts/los/clcs_new/submissions_files/rus01/ CLCS_01_2001_LOS_DNKtext.pdf>. Acesso em: 25 abr. 2015. 41 NORWAY. Notification regarding the submission made by the Russian Federation to the Commission on the Limits of the Continental Shelf, 2 April 2002. Disponível em: <http://www.un.org/depts/los/clcs_new/ submissions_files/rus01/CLCS_01_2001_LOS_NORtext.pdf $>$. Acesso em: 25 abr. 2015. Tradução do original: "Federation has not yet been settled and is the object of ongoing consultations. The unresolved delimitation issue in the Barents Sea is therefore to be considered as a "maritime dispute" for the purpose of rule 5 (a) Annex I to the Rules of Procedure of the Commission".

42 UNITED STATES OF AMERICA. Notification regarding the submission made by the Russian Federation to the Commission on the Limits of the Continental Shelf, 18 March 2002. Disponivel em: <http:// www.un.org/depts/los/clcs_new/submissions_files/rus01/ CLCS_01_2001_LOS_USAtext.pdf>. Acesso em: 25 abr. 2015. Tradução do original: "[...] believes that the submission has major flaws as it relates to the continental shelf in the Arctic [...] The Russian Federation submission is particularly complex and should be considered in a deliberate manner". 
Guerra Mundial. Nesse sentido:

Os mapas ilustram como águas russas a zona econômica exclusiva e a plataforma continental ao redor das Quatro Ilhas, que são território japonês inerente [...] A situação decorrente da ocupação ilegal das Quatro Ilhas pela antiga União Soviética depois do término da Segunda Guerra Mundial tem continuado até hoje [...] Pelos motivos acima mencionados, o Governo do Japão solicita à Comissão, no exame da submissão da Federação Russa, não tomar qualquer medida que possa prejudicar a questão territorial das Quatro Ilhas ou a delimitação da plataforma continental e da zona econômica exclusiva entre o Japão e a Federação Russa [...]. ${ }^{43}$

ii) na submissão apresentada pelo Brasil em 2004, também houve uma notificação de um terceiro Estado. Nesse caso, diferentemente, do que ocorreu no pleito russo, não se tratava de um país vizinho ou com limites marítimos próximos, mas dos Estados Unidos. A notificação norte-americana registrou suas diferenças em relação à espessura dos sedimentos apresentados na proposta brasileira e a espessura dos sedimentos encontrada nos registros públicos disponibilizados:

Em diversos pontos, os Estados Unidos observaram que há diferenças entre a espessura dos sedimentos apresentados no resumo brasileiro e a espessura dos sedimentos encontrada nos registros públicos disponibilizados [...] os Estados Unidos sugerem que a Comissão pode querer examinar os dados da espessura sedimentar do Brasil com atenção. ${ }^{44}$

Em outro ponto da notificação dos Estados Unidos, a oposição refere-se à cadeia de Vitória-Trindade, nes-

43 JAPAN. Notification regarding the submission made by the Russian Federation to the Commission on the Limits of the Continental Shelf. 14 March 2002. Disponível em: <http://www.un.org/depts/los/clcs_new/ submissions_files/rus01/CLCS_01_2001_LOS_JPNtext.pdf>. Acesso em: 25 abr. 2015. Tradução do original: "The maps illustrate as Russian waters the exclusive economic zone and the continental shelf around the Four Islands, which are inherent Japanese territory [...] The situation arising from the illegal occupation of the Four Islands by the former Soviet Union after the end of World War II has continued to this day [...] For the above-mentioned reasons, the Government of Japan requests the Commission, in its consideration of the submission by the Russian Federation, not to take any action that would prejudge the territorial issue of the Four Islands or delimitation of the continental shelf and the exclusive economic zone between Japan and the Russian Federation [...]".

44 UNITED STATES OF AMERICA. Notification regarding the submission made by the Brazil to the Commission on the Limits of the Continental Shelf, 9 September 2004. Disponível em: < http:/ / www.un.org/ Depts/los/clcs_new/submissions_files/bra04/clcs_02_2004_los_ usatext.pdf>. Acesso em: 25 abr. 2015. Tradução do original: "In several places, the United States observed that there are differences between the sediment thickness as presented in the Brazilian summary and the sediment thickness derived from the publicly available sources $[\ldots]$ the United States suggests that the Commission may want to examine Brazil's sediment thickness data carefully". ses termos:

Os Estados Unidos têm dúvidas de que essa região ["Vitória-Trindade"] faça parte da margem continental brasileira além das 200 milhas marítimas a partir das linhas de base das quais se mede a largura do mar territorial. Os Estados Unidos sugerem que a Comissão tenha uma abordagem cuidadosa no exame desta região. ${ }^{45}$

Contudo, a Comissão não aceitou a notificação enviada pelos Estados Unidos, mesmo reconhecendo que o Anexo II da CNUDM e o Regulamento da CLPC estabelecem a função que os demais Estados podem desempenhar no exame dos dados e do material a ser apresentado pelo Estado costeiro sobre os limites exteriores da plataforma continental além das 200 milhas marítimas.

No entendimento da Comissão, somente os Estados com costas adjacentes, confrontantes ou outras controvérsias territoriais ou marítimas pendentes podem fazer tal solicitação à Comissão. Dessa forma, pediu à subcomissão que examinava o pleito brasileiro que desconsiderasse as observações da carta dos Estados Unidos durante o exame da submissão brasileira ${ }^{46}$. Posteriormente, o representante dos Estados Unidos manifestou sua contrariedade, afirmando que não existe nenhum óbice no Anexo II da CNUDM à que a CLPC aceitasse as considerações de outros Estados. ${ }^{47}$

Para Edwin Egede, ainda que outros Estados e a Autoridade Internacional dos Fundos Marinhos não tenham em termos estritos possibilidade de colocar questionamentos sobre a proposta de plataforma continental estendida, esses terceiros interessados também teriam interesse em proteger os recursos da Área 3/4

45 UNITED STATES OF AMERICA. Notification regarding the submission made by the Brazil to the Commission on the Limits of the Continental Shelf, 9 September 2004. Disponível em: < http:/ / www.un.org/ Depts/los/clcs_new/submissions_files/bra04/clcs_02_2004_los_ usatext.pdf $>$. Acesso em: 25 abr. 2015. Tradução do original: "The United States doubt whether the feature in question ["Vitoria Trindade Ridge"] is part of Brazil's continental margin beyond 200 nautical miles from the baselines which the territorial sea is measured. The United States suggests that the Commission takes a cautious approach with regard to this feature".

46 CLCS/42, 14 September 2004. Statement by the Chairman of the Commission on the Limits of the Continental Shelf on the progress of work in the Commission.

47 UNITED NATIONS. Carta de 25 de outubro de 2004 da vicerepresentante dos Estados Unidos embaixadora Anne W. Patterson ao Subsecretário-Geral e Consultor Jurídico das Nações Unidas Sr. Nicolas Michel. Disponível em: <http://www.un.org/depts/los/clcs_ new/submissions_files/bra04/clcs_2004_los_usatext_2.pdf $>$. Acesso em: 25 abr. 2015. 
patrimônio comum da humanidade $3 / 4$, considerando o fato de que o aumento da plataforma continental estendida representa uma diminuição da Área. Assim, para Egede, a CLPC não deveria ignorar as comunicações de outros Estados e da própria Autoridade Internacional dos Fundos Marinhos, mas ao contrário, considera-las nos seus méritos no sentido de determinar se são ou não pertinentes. ${ }^{48}$

\section{B) Consentimento prévio}

A outra hipótese prevista no parágrafo 5(a) do Anexo I do Regulamento da Comissão é a de que sejam examinadas uma ou mais submissões em áreas sob disputa, desde que haja consentimento prévio de todos Estados que estejam envolvidos na controvérsia. Nenhuma submissão, contudo, foi encaminhada à CLPC nesses termos.

Alguns Estados costeiros apresentarem submissões conjuntas de limites exteriores (joint submissions). Esse tipo de proposta conjunta tem uma série de vantagens para os Estados envolvidos, como por exemplo, cooperação internacional, diminuição de custos e, mais importante, a possibilidade de que a Comissão faça recomendações "definitivas e obrigatórias" sobre toda a área envolvida, evitando, dessa maneira, a disputa sobre áreas sobrepostas, se houvesse a submissão de propostas apresentadas em separado.

Veja-se, por exemplo, a submissão conjunta apresentada por França, Irlanda, Espanha e Reino Unido na área do mar Celta e da baía de Biscaia:

\footnotetext{
[...] a submissão anexa é de natureza conjunta, compreendendo um único projeto preparado coletivamente e de forma colaborada pelos quatro Estados costeiros. Para cada um dos quatro Estados costeiros a submissão conjunta anexa representa uma submissão parcial no tocante à parcela dos limites exteriores da plataforma continental pertencente a todos os quatro Estados costeiros que se encontra além das 200 milhas marítimas das linhas de base a partir das quais se medem seus respectivos mares territoriais. Essa parte da plataforma não é objeto de qualquer disputa e, na perspectiva dos quatro Estados costeiros, seu exame pela Comissão não prejudicará os assuntos relacionados com a delimitação de fronteiras entre os quatro Estados costeiros e com os demais Estados. ${ }^{49}$
}

48 EGEDE, Edwin. Submission of Brazil and Article 76 of the Law of the Sea Convention (LOSC) 1982. The International Journal of Marine and Coastal Law, v. 21, n. 1, p. 41, 2006.

49 UNITED NATIONS. Commission on the Limits of the Continental Shelf (CLCS) Outer limits of the continental shelf beyond 200 nautical miles from the baselines: Submissions to the Commission: Joint submission
Outras submissões conjuntas apresentadas à CLPC foram: Ilhas Maurício e Seicheles na região do "Mascarene Plateau" (CLCS/62, 1 December 2008), Estados Federados da Micronésia, Papua-Nova Guiné e Ilhas Salomão relativa ao "Ontongo Java Plateau" (CLCS/66, 5 May 2009), Malásia e Vietnã na parte sul do Mar da China Meridional (CLCS/64, 6 May 2009), França e África do Sul na área do arquipélago de Crouzet e das ilhas do Príncipe Eduardo (CLCS/68, 6 May 2009) e Cabo Verde, Gâmbia, Guiné, Guiné-Bissau, Mauritânia, Senegal e Serra Leoa nas áreas do oceano Atlântico adjacente a costa ocidental da África (encaminhada à Comissão em 25 de setembro de 2014). ${ }^{50}$

\section{Considerações finais}

A Comissão de Limites da Plataforma Continental é um órgão técnico criado pela Convenção das Nações Unidas sobre o Direito do Mar para examinar os dados apresentados pelos Estados costeiros sobre os limites exteriores da plataforma continental, ou seja, além das 200 milhas marítimas, nos termos do artigo 76 da CNUDM.

Os trabalhos da Comissão iniciaram-se de fato quando a Federação Russa apresentou a primeira submissão estatal em dezembro de 2001. E, desde esse momento, houve considerável incremento no volume de trabalho da CLPC. Além disso, o número de Estados costeiros que já fizeram ou que ainda farão submissões à Comis-

by France, Ireland, Spain and the United Kingdom of Great Britain and Northern Ireland. Disponível em: <http://www.un.org/ depts/los/clcs_new/submissions_files/submission_frgbires.htm $>$. Acesso em: 25 abr. 2015. Tradução do original: “[...] the enclosed submission is of a joint nature, comprising a single project prepared collectively and collaboratively by the four coastal States. For each of these four coastal States the enclosed joint submission represents a partial submission in respect of a portion only of the outer limits of the continental shelf appurtenant to all four coastal States that lie beyond 200 nautical miles from their baselines from which the breadth of their respective territorial seas are measured. This portion of shelf is not the subject of any dispute and, in the view of the four coastal States, its consideration by the Commission will not prejudice matters relating to the delimitation of boundaries between the four coastal States and any other States".

50 UNITED NATIONS. Submissions, through the Secretary-General of the United Nations, to the Commission on the Limits of the Continental Shelf, pursuant to article 76, paragraph 8, of the United Nations Convention on the Law of the Sea of 10 December 1982. Disponível em: <http:// www.un.org/Depts/los/clcs_new/commission_submissions. htm>. Acesso em: 25 abr. 2015. 
são é cerca de quatro vezes superior ao originalmente imaginado durante os trabalhos da III Conferência das Nações Unidas sobre o Direito do Mar (1973-1982).

Agregue-se a esse fato uma crônica dificuldade financeira da Comissão que limita muito sua capacidade de funcionamento. O desejo por parte dos Estados costeiros de que as submissões sejam examinadas em um "prazo razoável" não encontra necessariamente resposta em maior apoio financeiro à CLPC. O aumento do número de semanas das iniciais vinte e uma, para vinte e seis, tampouco trará bons resultados, se persistir a situação em que alguns membros da Comissão não conseguem assistir todas as sessões de trabalhos por falta de recursos financeiros.

As intervenções de terceiros Estados, por meio de notificações endereçadas à CLPC, acabam trazendo um desafio adicional aos seus trabalhos. Isso ocorre porque ainda que sejam notificações de caráter técnico, a Comissão acaba se envolvendo em situações em que os interesses estatais são muito distintos e há um potencial conflitivo considerável $3 / 4$ caso das plataformas continentais estendidas no Ártico 3/4 ou, como ocorreu no caso da manifestação norte-americana no pleito brasileiro, em que a Comissão rejeitou o exame da notificação dos Estados Unidos, criando uma situação de contraposição aos interesses de terceiros Estados, ao limitar a apresentação de notificações somente aos Estados com costas adjacentes, confrontantes ou outras controvérsias territoriais ou marítimas pendentes à situação a ser examinada.

Dessa forma, levantando diversos pontos, com especial destaque para os desafios atuais e por meio da análise de casos concretos, o presente artigo procurou discutir o importante papel que vem desempenhando a Comissão de Limites da Plataforma Continental na delineação das plataformas continentais além do limite das 200 milhas marítimas.

\section{REFERÊNCIAS}

BARENTS OBSERVER. Denmark claims North Pole. Disponível em: <http://barentsobserver.com/en/ $\operatorname{arctic} / 2014 / 12 /$ denmark-claims-north-pole-15-12>. Acesso em: 25 abr. 2015.

CARLETON, Chris. Article 76 of the UN Convention on the Law of the Sea-implementation problems from the technical perspective. The International Journal of $\mathrm{Ma}$ rine and Coastal Law, v. 21, n. 3, p. 287-308, 2006.

CAVNAR, Anna. Accountability and the Commission on the Limits of the Continental Shelf: deciding who owns the ocean floor. Cornell International Law Journal, v. 42, p. 387-440, 2009.

EGEDE, Edwin. Submission of Brazil and Article 76 of the Law of the Sea Convention (LOSC) 1982. The International Journal of Marine and Coastal Law, v. 21, n. 1, p. 33-55, 2006.

ELFERINK, Alex G. Oude. Article 76 of the LOSC on the definition of the Continental Shelf: questions concerning its interpretation from a legal perspective. The International Journal of Marine and Coastal Law, v. 21, n. 3, p. 269-285, 2006.

GAU, Michael Sheng-Ti. Third Party Intervention in the Commission on the Limits of the Continental Shelf Regarding a Submission Involving a Dispute. Ocean Development \& International Law, v. 40, p. 61-79, 2009.

KUNOY, Bjorn. Disputed Areas and the 10-Year Time Frame: a Legal Lacuna? Ocean Development \& International Law, v. 41, p. 112-130, 2010.

MACNAB, Ron; PARSON, Lindsay. Continental Shelf Submissions: the record to date. The International Journal of Marine and Coastal Law, v. 21, n. 3, p. 309-322, 2006.

MCDORMAN, Ted L. The role of the Commission on the Limits of the Continental Shelf: a technical body in a political world. The International Journal of Marine and Coastal Law, v. 17, n. 3, p. 301-324, 2002.

SILVA, Alexandre Pereira da. A Rússia avança no Ártico. Boletim Meridiano 47, v. 15, n. 142, p. 20-27, mar./ abr. 2014.

SILVA, Alexandre Pereira da. O novo pleito brasileiro no mar: a plataforma continental estendida e o Projeto Amazônia Azul. Revista Brasileira de Politica Internacional, v. 56, n. 1, p. 104-125, 2013.

SMITH, Robert; TAFT, George. Legal Aspects of the Continental Shelf. In: COOK, Peter J.; CARLETON, Chris M. Continental Shelf Limits: the scientific and legal interface. Oxford: Oxford University Press, 2000. p. 17-24.

SUAREZ, Suzette V. The outer limits of the continental shelf: legal aspects of their establishment. Berlin: Springer, 2008. 
TAFT, George. The United Nations Convention on the Law of the Sea: The Commission on the Limits of the Continental Shelf - a Force for Enhancing Stability in the Oceans (or Not). Ocean Yearbook, v. 24, p. 151-169, 2010.
UNITED NATIONS. Division for Ocean Affairs and the Law of the Sea, Office of Legal Affairs. Training Manual for Delineation of the Outer Limits of the Continental Shelf beyond 200 nautical miles and for Preparation of Submissions to the Commission on the Limits of the Continental Shelf. New York: United Nations, 2006. 
Para publicar na Revista de Direito Internacional, acesse o endereço eletrônico www.rdi.uniceub.br ou www.brazilianjournal.org.

Observe as normas de publicação, para facilitar e agilizar o trabalho de edição. 